LAWRENCE LIVERMORE N A T IO N A L LABORATORY

2002-2003 Engineering

Accomplishments:

UCRL-TR-204274

Unconventional Nuclear

Weapons Detection

Jose E. Hernandez, John Valentine

May 20, 2004 
This document was prepared as an account of work sponsored by an agency of the United States Government. Neither the United States Government nor the University of California nor any of their employees, makes any warranty, express or implied, or assumes any legal liability or responsibility for the accuracy, completeness, or usefulness of any information, apparatus, product, or process disclosed, or represents that its use would not infringe privately owned rights. Reference herein to any specific commercial product, process, or service by trade name, trademark, manufacturer, or otherwise, does not necessarily constitute or imply its endorsement, recommendation, or favoring by the United States Government or the University of California. The views and opinions of authors expressed herein do not necessarily state or reflect those of the United States Government or the University of California, and shall not be used for advertising or product endorsement purposes.

This work was performed under the auspices of the U.S. Department of Energy by University of California, Lawrence Livermore National Laboratory under Contract W-7405-Eng-48. 


\section{2-2003 Engineering Accomplishments: Unconventional Nuclear Weapons Detection}

The Defense Threat Reduction Agency, DTRA, is a federal agency charged with safeguarding the nation from weapons of mass destruction, in particular nuclear weapons such as crude devices, and radiological dispersal devices (RDD), also known as dirty bombs. Both of which could be delivered using unconventional means such as by transporting them by a car or boat. Two years ago DTRA partnered with NNSA to evaluate commercially available technologies that could be deployed quickly to defend against threats posed by unconventional nuclear weapons under a program called the Unconventional Nuclear Warfare Defense (UNWD) Program. Lawrence Livermore National Laboratory (LLNL) was one

of several National laboratories that participated in this program, which consisted in developing, deploying, and demonstrating detection systems suitable for military base protection. Two key contributions to this program by the LLNL team were the development of two Radiation Detection Buoys (RDB) deployed at Naval Base in Kings Bay in Georgia, and the Detection and Tracking System (DTS) demonstrated at Fort Leonard Wood Missouri, headquarters for the Total Force's Maneuver Support Center (MANSCEN).

The RDB's were designed to detect the potential transportation of an unconventional nuclear or radiological weapon by a boat. The RDB's consisted of two commercial marine buoys instrumented with several types of detectors 
sensitive to gamma rays and neutrons, two key modes of energy emitted by radioactive materials. The engineering team selected a standard marine buoy as the overall system platform for this deployment since buoys are already designed to sustain the harsh marine environment, and also for their covertness, since once deployed, they look just like any other buoy on the water. Since this was the first time such a system was ever deployed, the team choose to instrument the buoys with a suite of different types of detectors with the goal to learn which detectors would be best suited for future deployments of this kind. This goal has now being achieved, and through a combination of computer modeling and experimental data, the team has gain the necessary knowledge to better understand the capabilities and limitations of RDB's, and the tradeoffs involve in the selection of the different detectors. The two LLNL RDB's are currently operational at Kings Bay, and the team is looking forward to another opportunity to design the next generation RDB's.

Similar to the RDB's, DTS was designed to detect the transportation of an unconventional nuclear or radiological weapon by a car. Due the high volume of vehicles in a typical road and the complexity of our road network, DTS uses a network of sensors, or nodes, to track the potential threat after the initial detection. This allows for some reasonable response time for any possible interdiction operation by law enforcement. It also provides an early warning of a threats en route to a potential target area, potentially minimizing the risk to the target and its surrounding community. Each DTS node is equipped with 
radiation detectors similar to those use in the buoys, a video camera for taking snap shots of the suspect vehicle, a GPS, and a wireless communication system. Whenever a node is triggered, sensor data from that node is reported back to a central computer where it is analyzed. A GIS (Geographical Information System) based display is used to show the operator a street map of the area protected by DTS, and the established trajectory of the threat vehicle(s) being track, as well as a real-time prediction of where the vehicle is heading next. This map display along with the vehicle photographs provides the kind of actionable information needed for performing an interdiction operation, and it also provides situational awareness of the overall threat. In addition, DTS was designed to be a rapidly deployable system, making it ideal for supporting special events, and a variety of other special operations.

Leveraging on the knowledge gained by these two one-of-a-kind innovative systems, the engineering team is currently supporting a variety of other similar Homeland Security projects for DHS and DoD, and expects to continue pushing the envelop in this challenging field of remote sensing of unconventional nuclear weapons. 